\title{
Papers
}

\section{Cost utility analysis of co-prescribed heroin compared with methadone maintenance treatment in heroin addicts in two randomised trials}

Marcel G W Dijkgraaf, Bart P van der Zanden, Corianne A J M de Borgie, Peter Blanken, Jan M van Ree, Wim van den Brink

\begin{abstract}
Objective To determine the cost utility of medical co-prescription of heroin compared with methadone maintenance treatment for chronic, treatment resistant heroin addicts.

Design Cost utility analysis of two pooled open label randomised controlled trials.

Setting Methadone maintenance programmes in six cities in the Netherlands.

Participants 430 heroin addicts.

Interventions Inhalable or injectable heroin prescribed over 12 months. Methadone (maximum $150 \mathrm{mg}$ a day) plus heroin (maximum $1000 \mathrm{mg}$ a day) compared with methadone alone (maximum $150 \mathrm{mg}$ a day). Psychosocial treatment was offered throughout.

Main outcome measures One year costs estimated from a societal perspective. Quality adjusted life years (QALYs) based on responses to the EuroQol EQ-5D at baseline and during the treatment period.

Results Co-prescription of heroin was associated with 0.058 more QALYs per patient per year $(95 \%$ confidence interval 0.016 to 0.099$)$ and a mean saving of $€ 12793$ (£8793, \$16 122) (€1083 to $€ 25229)$ per patient per year. The higher programme costs ( $€ 16$ 222; lower 95\% confidence limit $€ 15$ 084) were compensated for by lower costs of law enforcement ( $-€ 4129$; upper $95 \%$ confidence limit - €486) and damage to victims of crime ( $-€ 25374$; upper 95\% confidence limit - €16 625). The results were robust for the use of national EQ-5D tariffs and for the exclusion of the initial implementation costs of heroin treatment. Completion of treatment is essential; having participated in any abstinence treatment in the past is not. Conclusions Co-prescription of heroin is cost effective compared with treatment with methadone alone for chronic, treatment resistant heroin addicts.
\end{abstract}

\section{Introduction}

Though treatment supplemented with heroin improves the physical, mental, and social functioning of heroin addicts, ${ }^{1-3}$ we do not know whether the prescription or co-prescription of heroin is efficient from a societal perspective. Costly daily practice guidelines and safety procedures must be followed to enable the prescription of heroin-such as regular blood and urine monitoring of patients, trained healthcare workers working in pairs, and the presence of on-site security staff. ${ }^{3}$ Yet cost savings may result from reduced use of health care and less criminal behaviour by these patients. Political support for the implementation and financing of heroin treatment in target groups may not just depend on prevailing ethics but also on the programme's net costs in relation to its observed health benefits. We therefore performed a cost utility analysis alongside two Dutch trials comparing medical co-prescription of heroin with prescription of oral methadone alone as the best alternative treatment available.

\section{Methods}

\section{Design of the clinical studies}

Full details of the two Dutch heroin trials have been reported. ${ }^{3}$ Eligible patients were recruited from existing methadone maintenance programmes in six cities between mid-July 1998 and early October 2000 and randomised to treatment with methadone plus heroin (experimental group) or with methadone alone (control group). Separate trials were set up for patients who inhaled and those who injected. Participants were allowed to visit the treatment units three times a day seven days a week. Methadone was dispensed once a day. Participants in the experimental group received their methadone before the first administration of heroin and were allowed a maximum of $400 \mathrm{mg}$ heroin each visit and $1000 \mathrm{mg}$ a day. They accessed additional medical and psychosocial care as usual. At baseline and every two months during the treatment period trained interviewers assessed physical functioning, mental health, and social integration.

Of the 549 heroin addicts who participated in the trials, 119 received six months of control treatment followed by six months of experimental treatment. We performed the economic analysis with data from the 430 patients who were intended to receive the experimental or control treatment for a full year. We analysed the data from a societal perspective because the cost consequences of this intervention may well extend beyond the domain of health care.

\section{Health outcomes}

A generic approach to assessment of health outcomes is recommended to support decisions regarding allocation of healthcare resources. ${ }^{4}$ We used quality adjusted life years (QALYs) as our primary outcome measure, based on the EuroQol EQ-5D questionnaire. ${ }^{5}$ Each participant completed the EQ-5D at baseline and at months 6,10 , and 12 during treatment. Those included early in the trials also completed the questionnaire in the second 
month. Previous research had determined the utility of each observed health score profile on the EQ-5D based on the time trade-off elicitation technique during interviews with adults from the UK general population. ${ }^{6}$ Utilities range from -0.594, indicating serious health problems with mobility, self care, usual activities, pain/discomfort, and mood, to unity, indicating no problems at all. By convention, death takes the value of zero.

Heroin addiction is a chronic relapsing disorder with a fluctuating (on-off) course. Addicts can function as long as they receive the drugs as needed, while they deteriorate the moment the drug supply is interrupted. Given this on-off phenomenon in combination with the patients' good access to the trial drugs, we assumed that a person's health status is representative for the period in between the current observation and the previous one. ${ }^{7}$ Hence, we derived QALYs from multiplying the utility of each health state by the time in between the actual observation and the previous one and summing the results over the 12 month treatment period. In case of missing assessments, we carried forward the last observation.

\section{Use of resources, programme related travel, and crime}

We used clinical report forms and the European version of the addiction severity index (EuropASI $)^{8}$ to collect follow-up data on the use of healthcare resources, travel related to the programme, and illegal activities. The EuropASI was completed at the same intervals as the EQ-5D. We measured travel by multiplying the number of visits with twice the standardised distances to the relevant locations. ${ }^{9}{ }^{10}$

The EuropASI identifies the number of illegal activities resulting in law enforcement (police investigations, prosecution,

Table 1 Price indexed unit costs $(€)$ in 2001

\begin{tabular}{|c|c|c|c|}
\hline Resource & Unit & Unit costs & Source \\
\hline \multicolumn{4}{|l|}{ Maintenance programme } \\
\hline Methadone & $50 \mathrm{mg}$ & 0.55 & Committee Pharmacotherapeutic Help ${ }^{13}$ \\
\hline Methadone dispensation: & & & $\begin{array}{l}2001 \text { Ledger Municipal Health Services, Amsterdam and } \\
\text { Groningen }\end{array}$ \\
\hline Including housing & Intake & 4.17 & \\
\hline Excluding housing & Intake & 3.96 & \\
\hline Heroin & $1 \mathrm{~g}$ & 3.89 & Weighted market price ${ }^{14}$ for base and hydrochloride \\
\hline Heroin dispensation: & & & $\begin{array}{l}2001 \text { Ledger Municipal Health Services, Amsterdam and } \\
\text { Groningen }\end{array}$ \\
\hline Including rebuilding and housing & Intake & 30 & Plus: $\mathrm{CCBH}^{15}$ \\
\hline Excluding rebuilding, including housing & Intake & 29 & \\
\hline Excluding rebuilding and housing & Intake & 27 & \\
\hline \multicolumn{4}{|l|}{ Out-of-institution consultations } \\
\hline General practitioner & Visit & 17 & Dutch Manual for Costing $^{9}{ }^{12}$ \\
\hline Physiotherapist & Visit & 19 & Dutch Manual for Costing $^{912}$ \\
\hline Psychiatrist/psychologist/therapist & Visit & 104 & CTG Policy Measure III-686 ${ }^{16}$ \\
\hline Social/employment office worker & Visit & 17 & Academic Medical Centre 1999/2000 \\
\hline Company physician & Visit & 23 & Academic Medical Centre 1999/2000 \\
\hline Alternative/traditional medicine & Visit & 49 & Tariff NAAV 2000 \\
\hline \multicolumn{4}{|l|}{ Institutional outpatient consultations } \\
\hline Other addiction care programmes & Visit & 46 & CTG National tariffs 1999 \\
\hline General hospital & Visit & 59 & Dutch Manual for Costing $^{912}$ \\
\hline Psychiatric hospital & Visit & 72 & CTG Policy Measure III-686 $6^{16}$ \\
\hline Psychiatric hospital, part time treatment & Visit & 93 & CTG Policy Measure III-686 $6^{16}$ \\
\hline Regional agency for mental health care & Visit & 104 & CTG Policy Measure III-686 $6^{16}$ \\
\hline Crisis intervention centre & Visit & 341 & CTG Policy Measure III-686 ${ }^{16}$ \\
\hline \multicolumn{4}{|l|}{ Institutional inpatient stays/week } \\
\hline General hospital & Week & 2075 & Dutch Manual for Costing $^{17}$ \\
\hline Psychiatric hospital & Week & 1139 & CTG Policy Measure III-686 ${ }^{16}$ \\
\hline Psychiatric hospital, part time treatment & Week & 1258 & CTG Policy Measure III-686 ${ }^{16}$ \\
\hline Addiction care centre (physical) & Week & 858 & CTG Policy Measure III-686 ${ }^{16}$ \\
\hline Addiction care centre (psychiatric) & Week & 939 & CTG Policy Measure III-686 $6^{16}$ \\
\hline Crisis intervention centre & Week & 1720 & CTG Policy Measure III-686 $6^{16}$ \\
\hline \multicolumn{4}{|l|}{ Law enforcement } \\
\hline Police arrest and official report & Case & 2438 & Dutch Ministry of Justice $^{18} ; \mathrm{SCP}^{19}$ \\
\hline \multicolumn{4}{|l|}{ Conviction: } \\
\hline Prosecution & Case & 530 & Dutch Ministry of Justice ${ }^{18}$; SCP ${ }^{19}$ \\
\hline Adjudication & Case & 7135 & Dutch Ministry of Justice ${ }^{18} ; \mathrm{SCP}^{19}$ \\
\hline Imprisonment & Day & 145 & Agency for Judicial Institutions ${ }^{18}$; Dutch Ministry of Justice ${ }^{18}$ \\
\hline Probation & Contact & 840 & Dutch Ministry of Justice $^{18}$ \\
\hline \multicolumn{4}{|l|}{ Damage to victims } \\
\hline \multicolumn{4}{|l|}{ Company: } \\
\hline Theft & Incident & 100 & Hoofdbedrijfschap Detailhande $\left.\right|^{20}$ \\
\hline Burglary & Incident & 2000 & Hoofdbedrijfschap Detailhandel ${ }^{20}$ \\
\hline Civilian & Incident & 320 & $\mathrm{SCP}^{19}$ \\
\hline Programme related travel & & & Dutch Manual for Costing ${ }^{12}$; Central Bureau of Statistics ${ }^{10}$ \\
\hline Methadone location & Visit & 0.51 & \\
\hline Heroin location & Visit & 1.02 & \\
\hline
\end{tabular}


Table 2 Responses to EQ-5D during treatment after imputation of missing data and the related QALYs, by treatment group. Figures are means; medians (interquartile ranges)

\begin{tabular}{lrr} 
& Methadone plus heroin $(\mathrm{n}=193)$ & Methadone alone $(\mathrm{n}=237)$ \\
\hline EQ-5D utilities: & & \\
\hline Baseline & $0.740 ; 0.796(0.689-1)$ & $0.731 ; 0.796(0.689-0.883)$ \\
\hline Month 2* & $0.762 ; 0.796(0.691-1)$ & $0.718 ; 0.796(0.656-0.883)$ \\
\hline Month 6 & $0.771 ; 0.815(0.709-1)$ & $0.729 ; 0.796(0.656-0.942)$ \\
\hline Month 10 & $0.805 ; 0.848(0.725-1)$ & $0.729 ; 0.796(0.638-1)$ \\
\hline Month 12 & $0.813 ; 0.848(0.725-1)$ & $0.742 ; 0.796(0.673-1)$ \\
\hline QALYS & $0.788 ; 0.837(0.708-0.949)$ & $0.730 ; 0.771(0.620-0.903)$ \\
\hline
\end{tabular}

*Data available for participants in two of six treatment centres $(n=106)$.

†For differential QALYs, mean $(95 \% \mathrm{Cl}$ based on bias corrected and accelerated non-parametric bootstrapping; two tailed) 0.058 (0.016 to 0.099$)$, $\mathrm{P}=0.01$.

adjudication, and execution of sanctions). It also identifies the number of days of illegal activity by type of crime. However, it does not provide data on the number, type, and victims of illegal activities needed to estimate the potential damage to civilians or companies. Therefore, we performed a substudy using similar EuropASI interview conditions during February and March 2004 in 51 new patients during an extended phase of the Dutch heroin experiment. ${ }^{11}$ The patients matched the inclusion criteria of the original trials, were also in their first year of experimental treatment, and reported at least one day of acquisitive crime in the month before participating in the programme .

We did not measure production loss due to sick leave or lowered efficiency at work because unemployment or disability rates in the target population were expected to be high; nor did we measure the financial consequences of changes in patients' housing arrangements in the community, or the intangible costs of victims of crime and changes in the public's perception of safety.

\section{Unit costing and costs}

The costs included the direct medical costs of health care within the programme and elsewhere. The programme costs cover the costs of healthcare staff, security personnel, materials, overheads, and the depreciations (over 30 years, including interest) of initial rebuilding costs of the heroin dispensation facility. Furthermore, the direct personal costs of health related travel and the indirect costs of police investigations, prosecution, adjudication, imprisonment, resettlement, and damage to victims were included. Table 1 shows the key unit standardised costs ${ }^{12}$ by type of resource and by source. To derive unit costs for the year 2001 we used a general price index of $2 \%$ a year. ${ }^{9}$ Costs were calculated as the summed product of the volumes of resources used and their respective unit costs.

\section{Statistical analysis}

We performed intention to treat analyses and pooled the trial data for inhaling and injecting heroin addicts based on their similar treatment response. ${ }^{3}$ Volume and costs data for the first year after randomisation were averaged per patient. With a one year treatment period no discounting of costs and effects was performed. We hypothesised that in the experimental group, programme costs and related out-of-pocket expenses would be higher and other healthcare costs and costs related to crime would be lower. Because of skewed distributions, we assessed differences between groups by calculating 95\% confidence intervals for the mean differences after correction for bias and using accelerated non-parametric bootstrapping, drawing 25000 samples of the same size as the original sample separately for each group and with replacement. ${ }^{21}$ Point estimates of mean total costs and mean QALYs were used to calculate the incremental cost effectiveness ratio for experimental versus control treatment, again followed by the same bootstrap procedure to account for sampling variability. Similarly, we performed multi-way sensitivity analyses to investigate the robustness of the cost acceptability of experimental treatment (for willingness to pay values up to $€ 50000$ ) to plausible changes in key unit costs and to a Dutch time trade-off based health utility algorithm (Lamers LM, personal communication). We performed a subgroup analysis for patients with or without participation in abstinence-oriented treatment before baseline as such participation seemed to predict treatment effect. ${ }^{22}$ Another subgroup analysis was performed for patients who did or did not complete the 12 month treatment schedule.

\section{Results}

\section{Patients' characteristics and health outcomes}

Experimental $(n=193)$ and control $(n=237)$ patients were similar at baseline. The mean age was 39.3 (SD 5.7) years. Most patients were men $(80 \%, 345)$, of Dutch nationality $(92 \%, 397)$, of low education $(74 \%, 316)$, living independently or with relatives and friends (84\%, 359), and unemployed or disabled $(82 \%, 351)$. Major sources of income were social welfare (48\%, 203), disability benefit or pension $(12 \%, 50)$, and illegal activities or prostitution $(28 \%, 121)$. Sixty per cent $(256)$ inhaled heroin. Sixty one per cent (261) had previously attempted at least one treatment based on abstinence. On average, they spent $€ 900$ ( $£ 610 ; \$ 1133)$ a month on drugs. About once every three days, patients engaged in illegal activities to acquire money or drugs.

After randomisation, 13 participants in the experimental group and one in the control group rejected treatment. During the study period 45 and 32, respectively, discontinued treatment for various reasons. Thus $135(70 \%)$ in the experimental group and $204(86 \%)$ in the control group completed the full year of treatment. One hundred (51.8\%) participants in the experimental group responded to treatment compared with 68 (28.7\%) in the control group. Two deaths occurred, one in each group, but both were unrelated to treatment. Over one year, mean QALYs per patient (table 2) were significantly higher for experimental than control patients with a mean difference of 0.058 (95\% confidence interval 0.016 to 0.099 ).

\section{Use of resources and illegal activity}

Methadone intake was similar in both groups, at about $19 \mathrm{~g}$ a year. Experimental patients received $143 \mathrm{~g}$ heroin on average. The use of healthcare resources outside the programme was low with 8.6 and 7.4 consultations on average a year for experimental and control patients, respectively, and with each patient spending less than half a week as an inpatient (table 3 ).

Table 4 shows that participants in the experimental group engaged in criminal activities less often than those in the control group. They reported fewer days with crime against property (10.3 v 37.5), were arrested less often (2.1 $v 2.8$ times a year), were 


\begin{tabular}{|c|c|c|}
\hline Type of resource use & Methadone plus heroin ( $n=193)$ & Methadone alone $(n=237)$ \\
\hline \multicolumn{3}{|l|}{ Maintenance programme: } \\
\hline \multicolumn{3}{|l|}{ Methadone: } \\
\hline Dose (mg) & $19034(7615)^{*}$ & $19771(9764)^{*}$ \\
\hline No of intakes & $310(66)^{\star}$ & $287(86)^{*}$ \\
\hline \multicolumn{3}{|l|}{ Heroin: } \\
\hline Dose (mg) & $143581\left(91283^{*}\right)$ & - \\
\hline No of intakes & $556(305)^{*}$ & - \\
\hline Additional consultations & $4.6(12.2)^{*}$ & $2.5(8.3)^{*}$ \\
\hline \multicolumn{3}{|l|}{ Consultations: } \\
\hline \multicolumn{3}{|l|}{ Out of institution: } \\
\hline General practitioner & $193(487)$ & $225(600)$ \\
\hline Physiotherapist & $0(0)$ & $15(227)$ \\
\hline Psychiatrist/psychologist/therapist & $3(43)$ & $6(79)$ \\
\hline Social worker & $0(0)$ & $2(18)$ \\
\hline Social service worker & $13(96)$ & $16(114)$ \\
\hline Employment office worker & $1(14)$ & $3(39)$ \\
\hline \multicolumn{3}{|l|}{ Outpatient institutional: } \\
\hline Other addiction care programmes & $325(1683)$ & $265(975)$ \\
\hline General hospital & $222(1074)$ & $183(677)$ \\
\hline Psychiatric hospital & $4(58)$ & $7(104)$ \\
\hline Psychiatric hospital, part time treatment & $0(0)$ & $5(60)$ \\
\hline Regional agency for mental health care & $94(1296)$ & $14(128)$ \\
\hline Crisis intervention centre & $1(14)$ & $1(13)$ \\
\hline Self help support groups & $0(0)$ & $1(19)$ \\
\hline Total out of programme consultations & $856(2378)$ & $742(1438)$ \\
\hline \multicolumn{3}{|l|}{ Inpatient stays (weeks) } \\
\hline General hospital & 27 (153) & $28(165)$ \\
\hline Psychiatric hospital & $4(58)$ & $0(0)$ \\
\hline Addiction care centre & 14 (145) & $16(93)$ \\
\hline Crisis intervention centre & $0(0)$ & $5(58)$ \\
\hline Total & $45(216)$ & 49 (208) \\
\hline
\end{tabular}

less frequently convicted ( $0.25 v 0.54$ times), and stayed in prison almost one day less (11.7 $v 12.5$ days).

After we excluded patients with missing data or with more than 200 illegal activities a month $(\mathrm{n}=47$ remaining), the mean number of crimes against property per day of illegal activity with possible damage to third parties amounted to 3.4, with 2.5 (74\%) crimes against companies and $0.9(26 \%)$ against civilians.

\section{Costs and cost utility}

Tables 5 and 6 show the mean and median costs per patient.

Mean cost differences between the groups resulted from the maintenance programme, law enforcement, victim damage, and travel. The mean total net savings amounted to $€ 12793$. With these net savings and the higher mean QALYs (table 2), the experimental treatment was superior to the control treatment (figure).

\section{Sensitivity and subgroup analyses}

The dominance of the experimental treatment persisted $(95 \%$ upper limit - €12 911) when we used Dutch time trade-off based health utility values rather than UK values, with a difference in QALYs between the groups of 0.053 instead of 0.058 .

Table 4 Mean number of days with crime against property, arrests, convictions, days of imprisonment, and contacts with the probation officer, by treatment group. Figures are means per 100 participants (SD) unless stated otherwise

\begin{tabular}{lcc} 
Type of activity & Methadone plus heroin (n=193) & Methadone alone (n=237) \\
\hline No of days with crime against property & $10.3(34.8)^{*}$ & $37.5(78.6)^{*}$ \\
\hline Arrests resulting in prosecution: & $19(30)$ & $73(485)$ \\
\hline Possession or traffic of illegal drugs & $37(134)$ & $65(207)$ \\
\hline Crime against property & $2(16)$ & $16(82)$ \\
\hline Acts of violence & $88(256)$ & $74(204)$ \\
\hline Public disturbances & $8(49)$ & $14(120)$ \\
\hline Prostitution in public places & $0(0)$ & $1(19)$ \\
\hline Driving under influence of alcohol/drugs & $52(327)$ & $29(135)$ \\
\hline Other major road offences & $4(31)$ & $4(47)$ \\
\hline Other offences & $208(465)$ & $276(682)$ \\
\hline Total arrests & $25(96)$ & $54(204)$ \\
\hline Convictions for possession or traffic of illegal drugs, crime & $1165(4077)$ \\
$\quad$ against property, acts of violence & $4(44)$ & $1247(3967)$ \\
\hline Days of imprisonment & $19(116)$
\end{tabular}

*Mean (SD) 
Table 5 Comparison of per patient costs $(€)$ between treatment groups. Figures are means; medians (interquartile ranges)

\begin{tabular}{|c|c|c|}
\hline Type of costs & Methadone plus heroin ( $n=193$ ) & Methadone alone $(n=237)$ \\
\hline \multicolumn{3}{|l|}{ Medical costs: } \\
\hline \multicolumn{3}{|l|}{ Maintenance programme: } \\
\hline Methadone & $207 ; 200(152-263)$ & $216 ; 213(146-274)$ \\
\hline Heroin & $559 ; 358(265-818)$ & - \\
\hline Intakes and additional care & 16 868; 18798 (11 036-23 422) & 1196; 1318 (1072-1476) \\
\hline Total programme costs & 17 634; 19600 (11 550-24 558) & $1412 ; 1534$ (1195-1748) \\
\hline Out of institution consultations & $39 ; 0(0-35)$ & $52 ; 0(0-35)$ \\
\hline Institutional, outpatient consultations & $387 ; 0(0-177)$ & $259 ; 0(0-227)$ \\
\hline Institutional, inpatient stays & $734 ; 0(0-0)$ & $816 ; 0(0-0)$ \\
\hline Total other healthcare costs & $1160 ; 52(0-308)$ & $1126 ; 52(0-377)$ \\
\hline \multicolumn{3}{|l|}{ Law enforcement costs: } \\
\hline Police investigations & $5091 ; 0(0-7314)$ & $6748 ; 0$ (0-7314) \\
\hline Prosecution and adjudication & 1946; $0(0-0)$ & $4172 ; 0(0-0)$ \\
\hline Imprisonment and resettlement & $1719 ; 0(0-0)$ & $1965 ; 0(0-580)$ \\
\hline Total law enforcement costs & $8756 ; 0$ (0-9752) & $12885 ; 2438(0-14628)$ \\
\hline Costs of damage to victims & $9617 ; 0(0-0)$ & 34 991; 0 (0-28 007) \\
\hline Health related travel & $600 ; 637(428-788)$ & $146 ; 161$ (131-181) \\
\hline Total costs & 37 767; 26104 (18 544-39 554) & 50 560; 11847 (1987-51 530) \\
\hline
\end{tabular}

The programme costs of experimental treatment included the costs of rebuilding existing treatment centres. Exclusion of these initial implementation costs reduced the unit costs per heroin dispensation from $€ 30.32$ to $€ 28.64$ and strengthened the superiority of experimental over control treatment (95\% upper limit -€30 953).

Having participated in any abstinence-oriented treatment in the past did not substantially influence the effectiveness of the experimental treatment. For willingness-to-pay values between $€ 5000$ and $€ 50000$, the cost acceptability of experimental

Table 6 Differential costs per patient $(€)$ in treatment groups (methadone plus heroin $v$ methadone alone). Figures are differential mean costs $(95 \%$ confidence limit or interval based on bias corrected and accelerated non-parametric bootstrapping; one or two tailed, depending on hypothesis)

Cost $(€)$

\begin{tabular}{lc}
\hline Total programme costs & 16222 (lower limit $15084 ; \mathrm{P}<0.0001$ ) \\
\hline Total other healthcare costs & 34 (upper limit 659) \\
\hline Total law enforcement costs & -4129 (upper limit $-486 ; \mathrm{P}=0.03$ ) \\
\hline Costs of damage to victims & -25374 (upper limit -16 625; $\mathrm{P}<0.0001$ ) \\
\hline Health related travel & 456 (lower limit $417 ; \mathrm{P}<0.0001$ ) \\
\hline Total costs & -12793 (-25 229 to -1 083; $\mathrm{P}=0.032)$
\end{tabular}

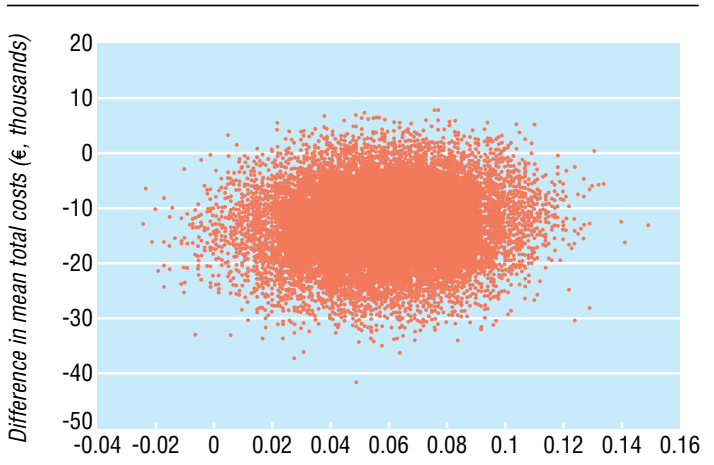

Difference in mean $Q A L Y_{S}$

Cost effectiveness plane, showing differences between experimental treatment (methadone plus heroin) and control treatment (methadone alone) after 25000 bootstrap replications. Vertical axis shows differences in mean total costs, horizontal axis shows differences in mean QALYs. The experimental treatment generated lower costs and more QALYs than the control treatment in $98 \%$ of all replications against control treatment ranged from $89 \%$ to $96 \%$ for patients with at least one previous abstinence attempt and from $96 \%$ to $97 \%$ for patients without such attempt.

Completion of treatment strongly influenced the programme's efficiency. The cost acceptability of experimental against control treatment for willingness-to-pay values up to $€ 50000$ did not exceed 32\% in case of non-completers. For treatment completers, however, the cost acceptability was higher than $99 \%$ for willingness-to-pay values of $\geq € 5000$.

\section{Discussion}

In this analysis of maintenance treatment for heroin addicts, the costs of the experimental treatment (methadone plus heroin) were higher than with the control treatment (methadone alone), but these higher costs were offset by savings for law enforcement and victim damage. The cost utility results are strikingly in favour of the experimental treatment at acceptable willingness-to-pay values per QALY. Others have found similar offsets of the higher costs of medical care by reduced costs of law enforcement and reduced costs of crime against property. ${ }^{23}{ }^{24}$ However, potential savings from reduced crime might not always turn into actual savings-for instance, due to labour contracts. Moreover, our participants were chronic, treatment resistant heroin addicts, and so our results cannot be generalised to heroin addicts who have not previously received methadone maintenance treatment.

This economic evaluation of heroin treatment was part of a randomised trial rather than within a single group before and after study. ${ }^{23}$ Compared with other addiction studies that included methadone maintenance treatment as reference care, we used a sufficiently long observation period of 12 months rather than a potentially suboptimal ${ }^{25}$ six months. ${ }^{26}$ Furthermore, we took a societal rather than provider perspective, ${ }^{26}{ }^{27}$ thereby paying attention to outcomes like reductions in crime that also matter to policy makers. ${ }^{28} 29$

Prolonged monitoring after planned discontinuation of experimental treatment after 12 months indicated substantial deterioration among responders to treatment. ${ }^{3}$ Most patients need lifetime treatment with methadone plus heroin, which is consistent with the chosen depreciation period for the initial rebuilding costs. In the long run, however, these rebuilding costs might have a larger impact on the costs per visit because the yearly number of visits may decrease for several reasons. The 


\section{What is already known on this topic}

Supervised medical prescription of methadone plus heroin is feasible, safe, and effective with clinically relevant improvements in physical health, mental status, and social functioning (including substantial reductions in criminal behaviour) in chronic, treatment resistant heroin addicts

\section{What this study adds}

From a societal perspective supervised medical prescription of methadone plus heroin is less costly than methadone maintenance treatment

The medical co-prescription of heroin is beneficial in terms of quality adjusted life years (QALYs)

Medical co-prescription of heroin is cost effective in patients who have previously failed to respond to methadone treatment

cohort of eligible patients will probably reduce in size due to low accrual rates and maybe increasing successful abstinence attempts after prolonged experimental treatment. Furthermore, patients who do not respond will stop receiving co-prescribed heroin. To limit the future impact of the capital costs on the costs per visit the unit should in time develop into a multifunctional intensive care facility including, for instance, the treatment of patients with HIV and other chronic diseases.

At baseline, most participants were unemployed or too disabled to work. If measured, production losses based on the friction cost method ${ }^{30}$ would probably have been low. A participant's improved health status and functioning might enable a return to paid work. Such change benefits the individual but does not necessarily lead to production gains for society at large because another (healthy) person might accept the job instead.

\section{Limitations}

The EQ-5D is generally accepted as an instrument of choice in economic evaluations. Little is known, however, about its reliability and validity in drug addicts. Although our conclusions may be robust, further study is needed into the use of the EQ-5D in such patients.

Compared with Dutch time trade-off based values, the use of time trade-off based UK health utility values overestimated the differences in QALYs. Consequently, the estimate of cost effectiveness of the experimental treatment is conservative.

The modest difference in costs of law enforcement between experimental and control patients compared with the difference in costs of damage to victims may result from law enforcement related to offences committed before study inclusion. If so, the real economic benefit from avoided crime in case of experimental treatment is underestimated.

Contributors: MGWD, CAJMdB, WvdB, and JMvR were responsible for concept and design. MGWD, BPvdZ, and PB were responsible for analysis. MGWD and BPvdZ wrote the first draft of the paper. All authors interpreted the data, revised the manuscript, and approved the paper. MGWD is guarantor.

Funding: The study was commissioned and financially supported by the Netherlands Ministry of Health, Welfare, and Sports.

Competing interests: None declared.

Ethical approval: The study was approved by the central committee on medical ethics (KEMO) and the substudy by the central committee on research involving human subjects (CCMO). All participants provided written informed consent.
1 Perneger TV, Giner F, Del Rio M, Mino A. Randomised trial of heroin maintenance programme for addicts who fail in conventional drug treatments. BMJ 1998;317:13-8. 2 Rehm J, Gschwend P, Steffen T, Gutzwiller F, Dobler-Mikola A, Uchtenhagen A. Feasibility, safety, and efficacy of injectable heroin prescription for refractory opioid addicts: a follow-up study. Lancet 2001;358:1417-20.

3 Van den Brink W, Hendriks VM, Blanken P, Koeter MWJ, Van Zwieten BJ, Van Ree JM. Medical prescription of heroin to treatment-resistant heroin addicts: two randomised controlled trials. BMJ 2003;327:310-5.

4 Gold MR, Siegel JE, Russell LB, Weinstein MC. Cost-effectiveness in health and medicine. New York: Oxford University Press, 1996.

Brooks R. EuroQol: the current state of play. Health Policy 1996;37:53-72.

6 Dolan P. Modeling valuations for EuroOol health states. Med Care 1997;35:1095-108.

7 Richardson G, Manca A. Calculation of quality adjusted life years in the published literature: a review of methodology and transparency. Health Economics 2004;13:1203-10. erature: a review of methodology and transparency. Heallh Economics 2004,13:1203-10. Kokkevi A, Hartgers C. European adaptation of a multidimensional assessment instrument for drug and alcohol dependents. Eur Addict Res 1995;1:208-10.

9 Oostenbrink JB, Koopmanschap MA, Rutten FFH. Handleiding voor kostenonderzoek. Methoden en richtlijnen voor economische evaluaties in de gezondheidszorg. Amstelveen: College voor Zorgverzekeringen, 2000.

10 Central Bureau of Statistics. Use of territory data 1996. www.cbs.nl (accessed 24 April 2003).

11 Van der Zanden BP, Dijkgraaf MGW. Type, frequency, and costs of illegal activities by heroin addicts in the Netherlands who are eligible for medical coprescription of heroin. Internal report. Amsterdam: Academic Medical Centre/Department of Clinical Epidemiology and Amsterdam: Acad

12 Oostenbrink JB, Koopmanschap MA, Rutten FFH. Standardisation of costs. The Dutch Oostenbrink JB, Koopmanschap MA, Rutten FFH. Standardisation of costs. The D
manual for costing in economic evaluations. Pharmacoeconomics 2002;20:443-54.

13 Van der Kuy A, ed. Farmacotherapeutisch Kompas 2000/2001. Amstelveen: College voor Zorgverzekeringen, 2000:965.

14 Huijsman IA. Letter iah/hg.030027. Utrecht: Central Committee on the Treatment of Heroin Addicts, 2003

15 Van den Brink W, Hendriks VM, Blanken P, Huijsman IA, Van Ree JM. Medical co-prescription of heroin; two randomised controlled trials. Utrecht: Central Committee on the Treatment of Heroin Addicts, 2002

16 College Tarieven Gezondheidszorg. Beleidsregel III-686; bijlage 2 bij circulaire TY/ma/III/ GGZ/01/13c. Utrecht: College Tarieven Gezondheidszorg (CTG), November 22, 2001.

17 Oostenbrink JB, Buijs-Van der Woude T, Agthoven M van, Koopmanschap MA, Rutten FFH. Unit costs of inpatient hospital days. Pharmacoeconomics 2003;21:263-71.

18 Schreuders MM, Huls FWM, Garnier WM, Swierstra KE. Criminaliteit en rechtshandhaving 1999; ontwikkelingen en samenhangen. The Hague: Ministry of Justice, WODC, 1999 19 Roes T, ed. De sociale staat van Nederland 2001. The Hague: Sociaal Cultureel Planbureau, 2001

20 Kaptein HJM, ed. Kerngegevens winkelcriminaliteit. The Hague: Hoofdbedrijfschap Detailhandel, January 2003.

21 Barber JA, Thompson SG. Analysis of cost data in randomized trials: an application of the non-parametric bootstrap. Stat Med 2000;19:3219-36.

22 Blanken P, Hendriks VM, Koeter MWJ, Van Ree JM, Van den Brink W. Matching of treatment-resistant heroin-dependent patients to medical prescription of heroin or treatment-resistant heroin-dependent patients to medical prescription of heroin or
oral methadone treatment: results from two randomised controlled trials. Addiction oral methadone

23 Gutzwiller F, Steffen T, eds. Cost-benefit analysis of heroin maintenance treatment. Medical prescription of narcotics. Vol 2. Basle: Karger, 2000.
pol

24 Brehmer C, Iten PX. Medical prescription of heroin to chronic heroin addicts in Switzerland-a review. Forensic Sci Int 2001;121:23-6.

25 Barnett PG, Hui SS. The cost-effectiveness of methadone maintenance. Mount Sinai J Med 2000;67:365-74.

26 Doran CM, Shanahan M, Mattick RP, Ali R, White J, Bell J. Buprenorphine versus methadone maintenance: a cost-effectiveness analysis. Drug Alcohol Depend 2003;71:295-302.

27 Masson CL, Barnett PG, Sees KL, Delucchi KL, Rosen A, Wong W, Hall SM. Cost and cost-effectiveness of standard methadone maintenance treatment compared with enriched 180-day methadone detoxification. Addiction 2004:99:718-26.

28 Sindelar JL, Jofre-Bonet M, French MT, McLellan AT. Cost-effectiveness analysis of addiction treatment: paradoxes of multiple outcomes. Drug Alcohol Depend 2004;73:4150.

29 Coast J. Is economic evaluation in touch with society's health values? $B M$ J 2004;329:1233-6.

30 Koopmanschap MA, Rutten FF, Van Ineveld BM, Van Roijen L. The friction cost method for measuring indirect costs of disease.J Health Econ 1995;14:171-89. (Accepted 13 April 2005)

bmj.com 2005;330:1297

Department of Clinical Epidemiology and Biostatistics (J1B-216) Academic Medical Centre, University of Amsterdam, PO Box 22700, 1100 DE Amsterdam, Medical Cen
Netherlands

Marcel G W Dijkgraaf senior researcher

Bart P van der Zanden researcher

Corianne A J M de Borgie senior researcher

Central Committee on the Treatment of Heroin Addicts (CCBH), Stratenum, Universiteitsweg 100, 3584 CG Utrecht, Netherlands

Peter Blanken researcher

Rudolf Magnus Institute of Neuroscience, University Medical Centre Utrecht Stratenum, Universiteitsweg 100, 3584 CG Utrecht, Netherlands Jan M van Ree professor

Department of Psychiatry Academic Medical Centre, University of Amsterdam, Amsterdam

Wim van den Brink professor

Correspondence to: M G W Dijkgraaf m.g.dijkgraaf@amc.uva.nl 